\title{
Um capítulo da história da modernidade estética: Debate sobre o Expressionismo. Análise e documentos (Textos de Ernst Bloch, Hanns Eisler, Georg Lukács, Bertolt Brechte Theodor W. Adorno)
}

Jordão Machado, Carlos Eduardo (2016).

San Pablo, Editora Unesp, 360 pp.

ISBN 978-85-393-0519-3

\section{María Belforte \\ CONICET, Universidad de Buenos Aires, Argentina}

Con la sutileza y el rigor necesarios para abordar un tema complejo y de múltiples facetas, Um capítulo da história da modernidade estética: Debate sobre o Expressionismo, de Carlos Eduardo Jordão Machado, logra presentar sin simplificaciones la magnitud y las ambivalencias de los problemas y perspectivas suscitados en los análisis de la relación entre el expresionismo y sus fundamentos histórico-políticos. El dilema que aborda el libro, en este caso, una segunda edición ampliada, es un ejemplo paradigmático del vínculo entre estética y política, que convocó a los intelectuales alemanes marxistas a tomar posición frente al movimiento vanguardista.

Machado introduce el caso de Gottfried Benn como disparador del problema del vínculo entre el expresionismo y el proceso de nazificación de la vida cultural y sus ambigüedades. El tema central que atraviesa el debate no escatima contradicciones y paradojas filosóficas e históricas: el expresionismo, acusado de constituir una forma ideológica compatible con y antecesora del fascismo sería condenado por el régimen nazi como una forma de "arte degenerado". Para romper con las lecturas simplificadoras, se cita la línea cultural oficial del nacionalsocialismo en las palabras de Börries von Münchhausen: "la disolución de la forma es directamente proporcional a la disolución de la moralidad de los contenidos" (p. 14). Machado muestra que la respuesta de Benn en defensa del expresionismo como forma revolucionaria del arte europeo pone en evidencia la fragilidad del movimiento que, aun cuando se adaptara a la ideología del nacionalsocialismo, sería condenado y relegado frente al estilo oficial del régimen, el "neoclasicismo pequeñoburgués" (p. 17).

En este trabajo, que combina la reflexión filosófica, la historia intelectual y la rigurosidad filológica de las fuentes, Machado pone en perspectiva de análisis distintos factores que resultan decisivos para la comprensión del debate sobre el expresionismo: desde el profundo y reiterado rechazo al liberalismo compartido tanto por posiciones de izquierda como de derecha, hasta la convicción de una Sonderbewusstsein de la cultura alemana.

A partir de esta presentación del debate, el segundo capítulo del libro enmarca la posición de Georg Lukács en la discusión de los años treinta en el contexto de su trayectoria intelectual de ese período y retoma, entre otros, el análisis del filósofo marxista de "Gran Hotel 'Abismo', menos conocido y comentado por la bibliografía pero de destacada importancia para la comprensión de la lectura lukácsiana antivanguardista. En este ensayo, la metáfora de la comodidad se pone al servicio de una fuerte crítica a los intelectuales alemanes, incapaces de construir una "opinión pública" propia debido a su "anticapitalismo romántico" o su ética izquierdista. El examen de Machado sobre el debate retoma los ensayos de Lukács y muestra los matices, las fortalezas y debilidades de su lectura del expresionismo como tendencia ideológica que desemboca en el fascismo. El 
irracionalismo, el anticapitalismo romántico y una cierta "ideología de la evasión" son elementos que conforman la Weltanschauung expresionista, según la lectura del filósofo húngaro.

A partir de la presentación de la crítica antivanguardista lukácsiana, Machado introduce la figura de Ernst Bloch en el debate y dedica dos capítulos al análisis y confrontación de los dos amigos en relación con la obra del segundo, Erbschaft dieser Zeit (Herencia de esta época). El estudio dedica un lugar importante a la discusión de la particular lectura de este libro de 1934 y al análisis del concepto de "asincronicidad" (Ungleichzeitigkeit), el cual explica la existencia de residuos del pasado no resuelto que engendran "falsa conciencia" y mitos. Las citas escogidas para apoyar los argumentos y el hilo conductor del análisis poseen un doble carácter iluminador: por una parte, funcionan como elementos de fundamento y especificación pero, por otra parte, también adquieren una especial contundencia al mostrar la actualidad del debate estudiado en el libro. Por ejemplo, cuando se cita a Bloch en relación con los análisis de las clases medias: "las clases medias no soportan ideológicamente la 'racionalización' y abandonan rápidamente la razón" (p. 61). Machado muestra también la posición excepcional de Bloch en relación con el expresionismo y con el método creativo de montaje, detalladamente analizado en el texto; su defensa de las vanguardias acerca por momentos su posición a la de Walter Benjamin, otro aspecto del debate que se plasma con agudeza en el estudio. Esta cercanía resulta esclarecedora del proyecto estético-político benjaminiano, más conocido en el ámbito académico hispanoparlante.

Como fundamento que contextualiza la discusión en torno al expresionismo, se analizan en este trabajo los antecedentes histórico-políticos del debate: se estudia la intervención de Bloch en el "Congreso Internacional de Escritores para la Defensa de la Cultura" de París en 1935 y su crítica al naturalismo; la creación de la revista Das Wort (La palabra), en la que tendrá lugar gran parte del debate; y la exposición de "Arte degenerado" organizada por el régimen nazi en 1937.

Entre las múltiples fuentes que se retoman, que involucran a figuras intelectuales como Klaus Mann, Alfred Kurella o Béla Balázs, se exponen con detenimiento las divergencias y cercanías de Lukács, Bloch y Benjamin, así como las críticas de Brecht y Adorno al filósofo húngaro. Algunas posiciones examinadas son prácticamente desconocidas en el ámbito hispanoparlante dado que muchas de las fuentes con las que trabaja Machado no han sido traducidas al español. La defensa de Bloch del programa estético de las vanguardias, por ejemplo, y en especial del expresionismo, se basa en un análisis fundamentado de manera histórico-política: el expresionismo se presentaba como el espacio ideológico que resguardaba elementos de una "segunda revolución", cuyos contenidos rebeldes, junto a los arcaicos, resultaron inaceptables para la ideología de los grandes negocios que necesitaban "empleados puntuales y domesticados". Al analizar a Bloch, Machado muestra las tenciones y contradicciones entre la estética y la política de grupos que acompañaron al nacionalsocialismo hasta su consolidación en el poder.

Finalmente, como anexo al análisis filológico de las fuentes, se ofrece al lector una selección de artículos que componen el debate, traducidos por el autor especialmente para este volumen. Los documentos incluyen las intervenciones de Ernst Bloch, Hans Eisler, Georg Lukács, Bertolt Brecht y Theodor W. Adorno. Este agregado funciona como herramienta de investigación en el contexto de una elaboración profunda de la historia intelectual: se trata de un debate fuertemente actual para la comprensión política de los medios y formas de expresión de lo humano. Debate sobre o expresionismo resulta un "capítulo de la modernidad estética", pero también un capítulo de la discusión marxista crítica menos conocida que sus protagonistas y que el autor refleja con la profundidad, sutileza y rigor filológico del abordaje multidisciplinario. 